Syntax Literate: Jurnal Ilmiah Indonesia p-ISSN: 2541-0849

e-ISSN: 2548-1398

Vol. 6, No. 3, Maret 2021

\title{
ANALISIS YURIDIS KEDUDUKAN JABATAN ANGGOTA POLRI AKTIF DI LUAR INSTITUSI POLRI DI TENGAH ISU DWI-FUNGSI POLRI
}

\author{
Adrianus Adhiwira Yoga Pradhana, Chairul Muriman Setyabudi dan Surya \\ Dharma \\ Sekolah Kajian Strategik Global Program Kajian Ilmu Kepolisian Universitas Indonesia \\ Email: mbahadhiwira@yahoo.com,cak_iir@yahoo.co.id dan surya_tendik@yahoo.com
}

\begin{abstract}
This research aims to juridically analyzing the positions of active POLRI members outside POLRI institutions, especially in ministries, agencies and commissions, then connecting with issues The dual function of the POLRI. This research is a normative juridical research with a statutory approach and a conceptual approach. The data used are secondary data. The results show that the placement of active POLRI members in ministries, institutions and commissions does not violate statutory regulations nor is a form of the dual function of POLRI. This is because the position of an active POLRI member still has a bearing on the police function even though he is serving outside the POLRI institution.
\end{abstract}

Keywords: active polri members, position outside the polri institution, the dual function of abri, police function.

\begin{abstract}
Abstrak
Penelitian ini bertujuan untuk menganalisis secara yuridis kedudukan jabatan anggota Polisi Republik Indonesia (POLRI) aktif di luar institusi POLRI terutama di kementerian, lembaga, dan komisi kemudian dihubungkan dengan isu Dwi Fungsi POLRI. Penelitian ini merupakan penelitian yuridis normatif dengan pendekatan perundangan-undangan dan pendekatan konseptual. Data yang digunakan adalah data sekunder. Hasil penelitian menunjukkan bahwa penempatan anggota POLRI aktif di kementerian, lembaga, dan komisi tidak melanggar peraturan perundangundangan dan juga tidak merupakan bentuk Dwi Fungsi POLRI. Hal ini dikarenakan jabatan anggota POLRI aktif tersebut masih memiliki keterkaitan dengan fungsi kepolisian walaupun bertugas di luar institusi POLRI.
\end{abstract}

Kata kunci: anggota polri aktif; jabatan di luar institusi polri; dwi fungsi polri; fungsi kepolisian

Coresponden Author

Email: mbahadhiwira@yahoo.com Artikel dengan akses terbuka dibawah lisensi

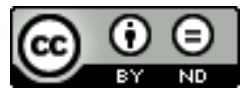


Adrianus Adhiwira Yoga Pradhana, Chairul Muriman Setyabudi dan Surya Dharma

\section{Pendahuluan}

Salah satu persoalan yang dihadapi oleh Polisi Republik Indonesia (POLRI) sejak beberapa tahun lalu adalah fenomena bottle-neck, khususnya sumbatan dalam perjalanan Komisaris Besar (Kombes) menuju bintang (berpangkat jenderal/Pati). Hal ini terlihat dari data susunan personel POLRI pada Gambar 1 dan Gambar 2. Dari data tersebut tampak adanya kesenjangan yang besar antara perwira menengah (Kombes) dan perwira tinggi (Pati). Akibatnya, kendati sudah memenuhi syarat atau eligible, banyak Kombes berkompetisi kemudian tidak kunjung naik jabatan menjadi pati sehingga mengakibatkan terjadinya kondisi bottle-neck kenaikan pangkat (Ridha \& Wijaya, 2020). Hal ini dikarenakan jabatan-jabatan yang tersedia untuk pati sudah terisi semua, terlebih lagi jumlah jenderal memang dibatasi. Kondisi semacam ini sempat diungkap oleh mantan Kapolri Tito Karnavian maupun Kapolri Idham Azim.

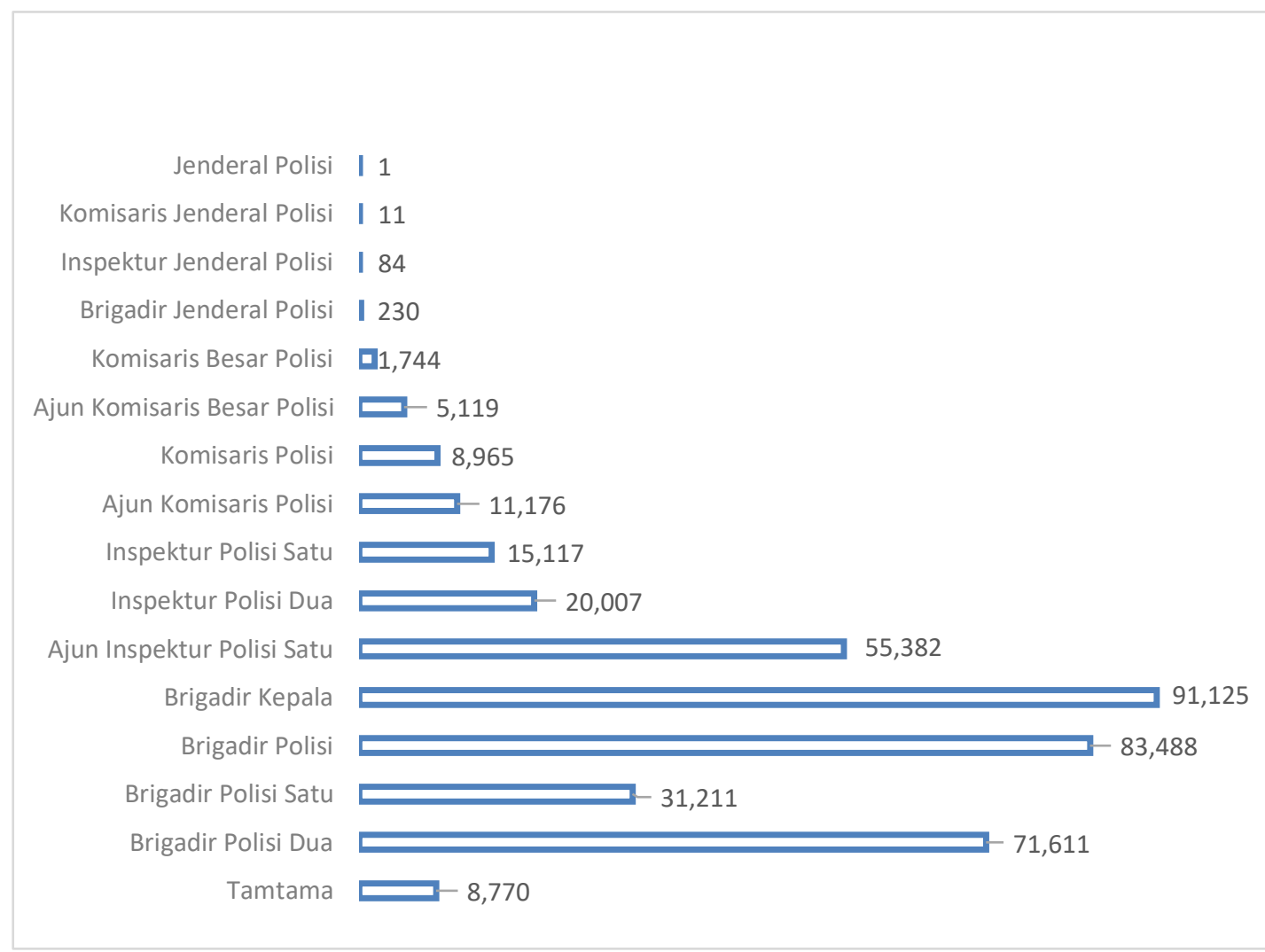

Gambar 1

Susunan Personel POLRI

Sumber: Baginfopers Robinkar SSDM POLRI, Oktober 2019 (Ridha \& Wijaya, 2020). 


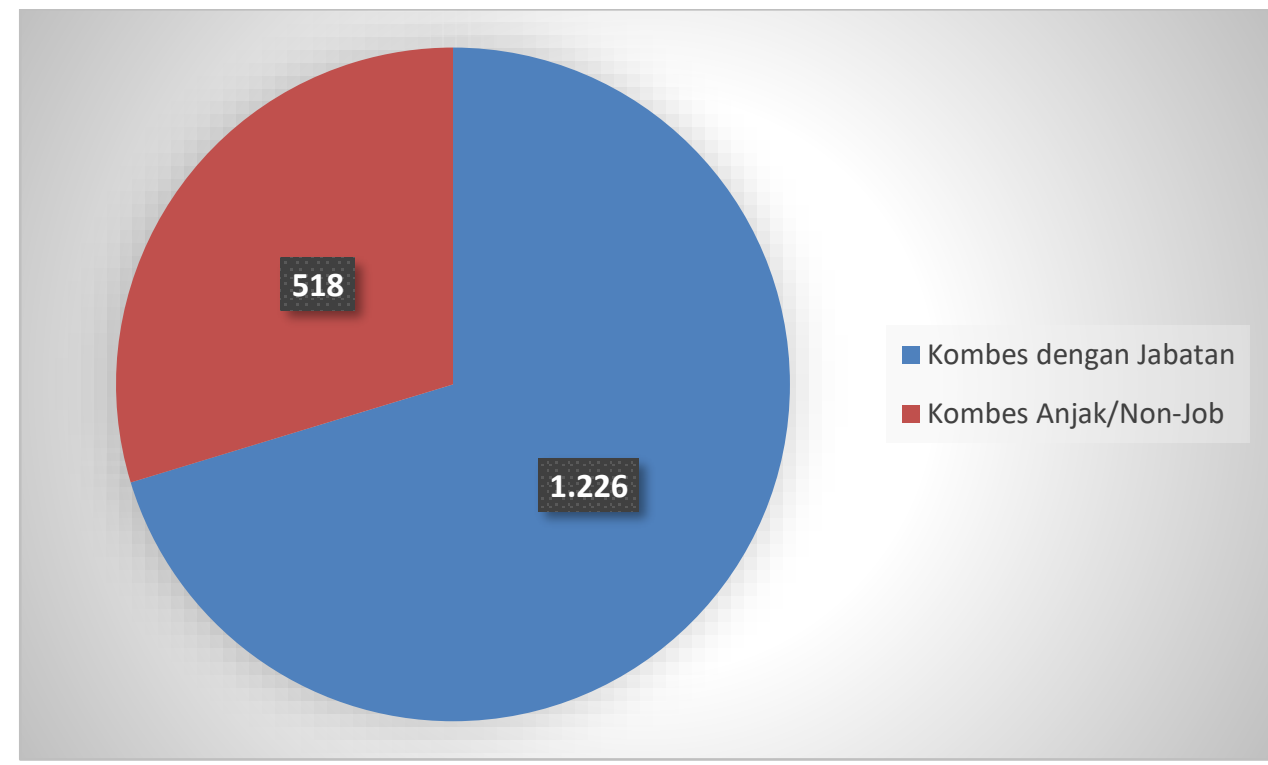

Gambar 2

Susunan Status Pamen Berpangkat Kombes

Sumber: Baginfopers Robinkar SSDM POLRI, Oktober 2019 (Ridha \& Wijaya, 2020)

Bila dibiarkan berkepanjangan, situasi kondisi bottle-neck tersebut tentu berimplikasi negatif. Selain kepada pembinaan karir bagi Perwira Menengah (Pamen) POLRI ke depannya, kondisi tersebut juga berdampak kepada pelaksanaan tugas dan fungsi POLRI sebagai pelayan publik (Ridha \& Wijaya, 2020). Untuk mengatasi permasalahan tersebut, POLRI telah mengambil berbagai langkah atau strategi dari memperpanjang masa dinas dalam kepangkatan; memperluas jabatan struktural bagi pangkat Kombes dan Brigadri Jenderal (Brigjen) atau jenderal bintang satu; menambah satuan kerja; hingga mengembangkan jabatan struktural di luar institusi POLRI (Ridha \& Wijaya, 2020).

Sehubungan dengan jabatan di luar institusi POLRI tersebut, sejumlah anggota POLRI aktif telah menduduki jabatan di kementerian, lembaga, komisi, dan sebagainya. Namun, pengisian jabatan oleh anggota POLRI aktif di sejumlah lembaga, kementerian, atau komisi tersebut ternyata telah memunculkan beragam isu. Salah satu yang mencuat di tengah masyarakat adalah adanya anggapan tentang Dwi Fungsi POLRI, yang mengingatkan kembali perihal Dwi Fungsi Angkatan Bersenjata Republik Indonesia (ABRI) di masa orde baru.

Berangkat dari latar belakang tersebut, studi ini berfokus menganalisis secara yuridis kedudukan jabatan anggota POLRI aktif di luar institusi POLRI terutama di kementerian, lembaga, dan komisi, kemudian dihubungkan dengan isu Dwi Fungsi POLRI yang sempat menjadi perhatian publik. Berdasarkan penelusuran, fokus studi serupa ini belum banyak dilakukan. (Fahrani, 2018) dalam studinya sebatas meneliti kriteria dan syarat jabatan di instansi pemerintah tertentu yang bisa diisi prajurit Tentara Nasional Indonesia (TNI) dan POLRI. (Limanjaya, 2020) meneliti penunjukan anggota POLRI aktif untuk menduduki jabatan di luar kepolisian ditinjau dari kepastian hukum. (Rivera, 2018) meneliti peralihan status anggota POLRI menjadi PNS. 
Penelitian dari Fahrani, Limanjaya, dan Rivera tersebut belum mengarah kepada analisis bagaimana kedudukan anggota POLRI aktif yang bertugas di luar institusi POLRI terutama di kementerian, lembaga, dan komisi dalam hubungannya dengan konteks isu Dwi Fungsi POLRI. Dari studi ini, peneliti berharap dapat memperjelas bagaimana kedudukan anggota POLRI aktif yang bertugas di luar institusi POLRI khususnya di kementerian, lembaga dan komisi sekaligus menerangkan apakah hal tersebut merupakan "Dwi Fungsi POLRI" atau bukan.

\section{Metode Penelitian}

Metode penelitian ini adalah penelitian yuridis normatif, yaitu menggambarkan bagaimana hubungan hukum positif dengan permasalahan yang diangkat (Soerjono dan Mamudji, 2011). Pendekatan yang digunakan adalah pendekatan perundang-undangan dan pendekatan konseptual. Pendekatan perundang-undangan dilakukan dengan menelaah peraturan perundang-undangan dan regulasi yang bersangkut paut dengan perkara atau permasalahan yang diangkat dalam penelitian ini (Marzuki, 2005). Pendekatan konseptual dilakukan dengan menganalisis permasalahan dilihat dari aspek konsep-konsep hukum yang melatarbelakanginya (Machmud, 2005). Data yang digunakan dalam penelitian ini adalah data sekunder. Data sekunder adalah data yang berasal dan dikumpulkan dari studi dokumen/kepustakaan (Soerjono, 2011). Adapun bahan-bahan tersebut dikelompokkan dalam tiga jenis.

Pertama, berupa bahan hukum primer seperti peraturan perundang-undangan yang relevan dengan masalah yang diangkat antara lain Undang-Undang No. 2 (dua) Tahun 2002 tentang POLRI; Peraturan Kapolri No. 4 (empat) Tahun 2017 Tentang Penugasan Anggota POLRI di Luar Struktur POLRI; Peraturan Polisi Nomor 12 Tahun 2018 Tentang Perubahan Perkap Nomor 4 (empat) Tahun 2017 Tentang Penugasan Anggota Polri di Luar Struktur Organisasi; Undang-Undang No. 34 (tiga puluh empat) Tahun 2004 tentang TNI; Undang-Undang No. 20 (dua puluh) Tahun 1982 Ketentuan Pokok Pertahanan Keamanan Negara; Undang-Undang No. 5 (lima) Tahun 2014A ASN; PP No. 11 (sebelas) 2017 tentang Manajemen PNS; dan PP No. 15 (lima belas) Tahun 2001 tentang Pengalihan Status Anggota TNI dan Anggota POLRI Menjadi PNS. Kedua, berupa bahan sekunder berupa buku-buku atau artikel-artikel ilmiah terkait teori-teori penegakan hukum, kepolisian, dan Dwi Fungsi ABRI. Ketiga, bahan tersier seperti yang berasal dari media elektronik atau sumber internet yang berhubungan dengan topik penelitian.

Delimitasi atau batasan area penelitian ini adalah seputar masalah dasar hukum kedudukan anggota POLRI aktif yang bertugas di luar institusi POLRI khususnya di kementerian, lembaga dan komisi. Penelitian ini memiliki keterbatasan (limitasi) dari sisi jenis data. Data yang disajikan terbatas pada data sekunder dan tidak menampilkan data primer yang berasal dari wawancara.

Analisis data yang digunakan penulis terbagi dalam tiga alur kegiatan. Pertama, tahap reduksi data. Dalam tahap reduksi ini, data yang sudah terkumpul disederhanakan dan digolongkan, kemudian mengeliminasi data yang tidak perlu atau tidak terkait dengan 
topik penelitian. Kedua, penyajian data. Dalam tahap penyajian data, data yang telah disederhanakan dan dikelompokkan disajikan dalam bentuk tabel untuk menghasilkan informasi yang bermakna sekaligus memudahkan pemahaman dan penarikan kesimpulan terkait dengan topik yang diteliti. Ketiga, memverifikasi dan menarik kesimpulan (Patilima, 2007). Pada tahap ini, data-data yang telah disajikan dinilai kembali untuk dilihat ketepatan dan kesesuaiannya dengan tujuan analisis guna ditarik menjadi kesimpulan sebagai jawaban dari permasalahan yang diajukan pada penelitian ini.

\section{Hasil dan Pembahasan}

\section{A. Penghapusan Dwi Fungsi ABRI: Dari Orde Baru Ke Era Reformasi}

Selama masa pemerintahan Orde Baru, POLRI maupun TNI tergabung dalam Angkatan Bersenjata Republik Indonesia (ABRI). Pada masa itu berlaku Dwi Fungsi ABRI yang mengacu pada pengertian bahwa ABRI mengemban dua fungsi yaitu sebagai kekuatan pertahanan dan keamanan (Hankam), disamping itu juga berfungsi sebagai kekuatan sosial politik sebagaimana dinyatakan dalam UU No. 20 Tahun 1982 Ketentuan Pokok Pertahanan Keamanan Negara (Rikan, 2014). Berdasarkan Dwi Fungsi ABRI saat itu, dalam fungsi sebagai kekuatan sosial politik, tidak sedikit anggota ABRI yang menduduki jabatan-jabatan sipil di pemerintahan mulai sebagai bupati, walikota, gubernur, pejabat eselon, menteri, duta besar, dan sebagainya.

Pasca Orde Baru terjadi perubahan paradigma dalam sistem ketatanegaraan di Indonesia, termasuk menyangkut ABRI. Di samping pemisahan POLRI dan TNI, terjadi pula penghapusan Dwi Fungsi ABRI yang ditandai dengan terbitnya peraturan perundang-undangan yang mengatur pembatasan pengisian jabatan di luar struktur organisasi baik bagi anggota TNI ataupun POLRI.

Di lingkungan TNI diterbitkan Undang-Undang No. 34 (tiga puluh empat) Tahun 2004 yang salah satu isinya mengatur pembatasan penempatan prajurit aktif di luar struktur organisasi TNI. Berdasarkan Undang-Undang TNI tersebut, prajurit aktif TNI dibatasi boleh bertugas di luar struktur organisasi di beberapa instansi saja seperti di instansi Koordinator Bidang Politik dan Keamanan Negara, Pertahanan Negara, Sekretaris Militer Presiden, Intelijen Negara, Sandi Negara, Lembaga Ketahanan Nasional, dan Dewan Pertahanan Nasional. Sementara itu, untuk anggota POLRI, terbit UU No. 2 (dua) Tahun 2002 tentang POLRI yang salah satu isinya mengatur anggota POLRI aktif harus mengundurkan diri atau pensiun dari Dinas Kepolisian jika menduduki jabatan di luar kepolisian. Terbitnya peraturan yang membatasi jabatan anggota TNI maupun POLRI aktif di luar struktur organisasi, ini menandakan penghapusan Dwi Fungsi ABRI di era Reformasi (Fahrani, 2018). 


\section{Tabel 1}

\section{Perbedaan Peran ABRI di Orde Baru dan Masa Reformasi}

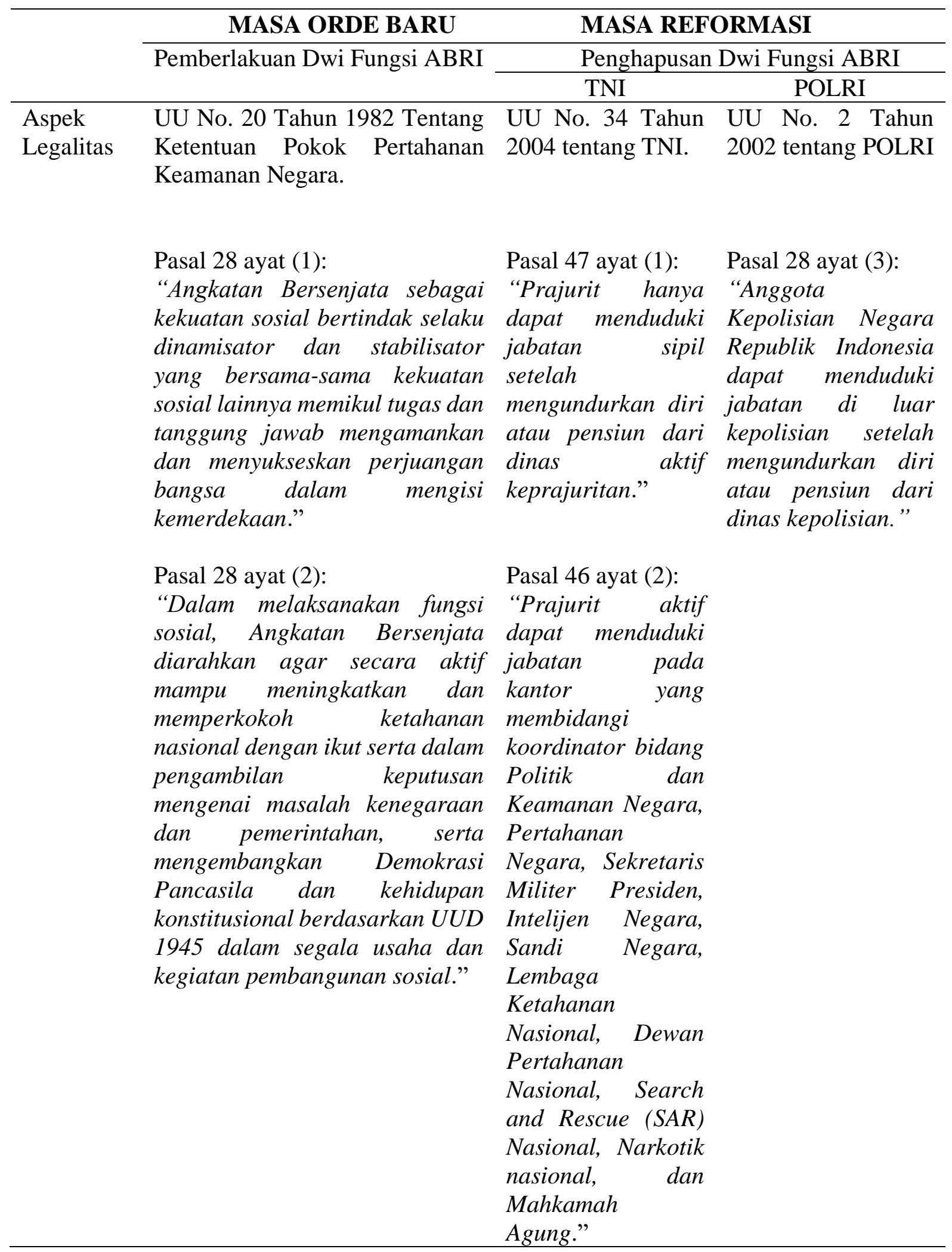




\section{B. Jabatan Anggota POLRI Aktif di Luar Institusi POLRI}

Sebagaimana dijelaskan di atas, di masa Reformasi telah terjadi penghapusan Dwi Fungsi ABRI. Dalam konteks anggota POLRI, Undang-Undang Nomor 2 (dua) Tahun 2002 telah mengatur bahwa anggota POLRI harus mengundurkan diri atau pensiun dari Dinas Kepolisian jika ingin menduduki jabatan di luar Kepolisian. Namun, ada anggota POLRI yang masih menduduki jabatan di luar struktur POLRI seperti di kementerian, lembaga, atau komisi seperti tersaji pada Tabel 2.

\section{Tabel 2}

\section{Anggota POLRI Menjabat di Luar Struktur Organisasi POLRI}

\begin{tabular}{lll}
\hline \multicolumn{1}{c}{ Anggota POLRI (Nama) } & \multicolumn{1}{c}{ Jabatan } \\
\hline Komjen Pol Boy Rafli Amar & $\begin{array}{l}\text { Kepala Badan Nasional Penanggulangan } \\
\text { Terorisme (BNPT) }\end{array}$ \\
\hline Komjen Pol Firli Bahuri & Ketua Komisi Pemberantasan Korupsi (KPK) \\
\hline Komjen Pol Heru Winarko & Kepala Badan Narkotika Nasional (BNN) \\
\hline $\begin{array}{l}\text { Komjen Pol Andap Budi } \\
\text { Revianto }\end{array}$ & Inspektur Jenderal KemenkumHAM \\
\hline Irjen Pol Reinhard Silitonga & Dirjen Pemasyarakatan KemenkumHAM \\
\hline Irjen Pol Setyo Wasisto & $\begin{array}{l}\text { Irjen di Kementerian Perindustrian } \\
\text { (Kemenperin) }\end{array}$ \\
\hline Brigadir Jenderal Adi Deriyan & $\begin{array}{l}\text { Staf Khusus bidang Keamanan Menteri } \\
\text { Pariwisata dan Ekonomi Kreatif (Menparekraf) }\end{array}$ \\
\hline
\end{tabular}

Sumber: www.cnninonesia.com

Bagaimanakah menilai posisi anggota POLRI aktif yang menduduki jabatan di sejumlah kementerian/lembaga/komisi tersebut? Apakah hal itu menunjukkan Dwi Fungsi ABRI?

Dalam konteks ini perlu dilihat lebih lanjut maksud frase "jabatan di luar kepolisian" yang terdapat pada Pasal 28 ayat (3) UU POLRI. Berdasarkan Penjelasan UU POLRI, yang dimaksud sebagai jabatan di luar kepolisian tersebut adalah jabatan yang tidak mempunyai sangkut paut dengan kepolisian atau tidak berdasarkan penugasan dari Kapolri.

Dengan demikian, anggota POLRI yang menduduki jabatan di luar institusi POLRI yang jabatan tersebut tidak berhubungan dengan fungsi kepolisian harus mengundurkan diri atau pensiun dari dinas kepolisian. Namun, apabila mempunyai sangkut paut dengan fungsi kepolisian, anggota POLRI tetap dapat menjabat di luar struktur kepolisian. Jadi, anggota POLRI masih tetap diperbolehkan menduduki jabatan di luar kepolisian sepanjang jabatan tersebut sesuai dengan bidang atau fungsi kepolisian (Limanjaya, 2020).

Untuk melihat jabatan anggota Polisi aktif di luar struktur organisasi POLRI seperti tersaji pada Tabel 2 apakah masih bersangkut paut dengan fungsi kepolisian, ini dapat dianalisis dengan membandingkan tugas maupun wewenang yang dimiliki oleh jabatan tersebut dengan fungsi kepolisian. 
Sebagaimana diatur dalam UU POLRI, fungsi kepolisian adalah di bidang (1) pemeliharaan keamanan dan ketertiban masyarakat; (2) penegakan hukum; serta (3) pemberian perlindungan, pengayoman, dan pelayanan kepada masyarakat. Dalam konteks Komjen Pol Firli Bahuri menjabat sebagai Ketua Komisi Pemberantasan Korupsi (KPK), meskipun yang bersangkutan masih aktif, hal tersebut tidaklah melanggar peraturan perundangan-undangan atau juga mengharuskan yang bersangkutan lebih dahulu mengundurkan diri atau pensiun dari dinas kepolisian. Ini karena jabatan di luar institusi POLRI yang diemban Komjen Pol Firli Bahuri masih memiliki sangkut paut dengan fungsi kepolisian, yakni fungsi penegakan hukum.

KPK merupakan instansi yang berwenang melakukan pemberantasan tindak pidana korupsi. Polisi dan lembaga KPK sama-sama melakukan penyidikan terhadap suatu tindak pidana. Karena tujuan, fungsi, dan wewenang yang dipunya KPK juga dimiliki oleh anggota kepolisian, maka jabatan Ketua KPK (yang diemban Komjen Pol Firli Bahuri) adalah jabatan yang dapat diisi oleh anggota POLRI tanpa yang bersangkutan harus mengundurkan diri atau pensiun dari dinas kepolisian. Demikian pula halnya dengan jabatan-jabatan lain di KPK yang masih berhubungan dengan fungsi kepolisian seperti penyidik. (Limanjaya, 2020).

Posisi jabatan yang diisi oleh Komjen Pol Boy Rafli Amar sebagai Kepala BNPT atau Komjen Pol Heru Winarko sebagai Kepala BNN juga merupakan jabatan yang masih mempunyai keterhubungan dengan fungsi kepolisian. BNN adalah Lembaga Pemerintah Non Kementerian (LPNK) yang mempunyai tugas di bidang pencegahan, pemberantasan penyalahgunaan dan peredaran gelap narkotika, psikotropika, prekursor dan bahan adiktif lainnya (kecuali bahan adiktif untuk tembakau dan alkohol). Adapun BNPT adalah LPNK yang membidangi penanggulangan terorisme. Mengingat BNN dan BNPT merupakan lembaga yang melakukan penyidikan terhadap suatu tindak pidana, pengisian jabatan sebagai Ketua BNN atau ketua BNPT oleh anggota POLRI aktif masih diperbolehkan sebab jabatan tersebut masih memiliki sangkut paut dengan fungsi kepolisian yakni fungsi penegakan hukum. Demikian pula bagi anggota POLRI aktif lainnya yang menduduki posisi jabatan-jabatan tertentu di kedua lembaga tersebut masih tetap diperbolehkan sejauh jabatan yang dipegang terkait dengan fungsi kepolisian.

Sebagaimana jabatan Ketua KPK, BNN atau BNN, begitu pula dengan jabatan Inspektur Jenderal Kementerian Perindustrian (Kemenprin) yang dijabat oleh Mantan Kadiv Humas Mabes POLRI Irjen Pol Setyo Wasisto. Posisi Inspektur Jenderal merupakan jabatan yang strategis di Kemenperin. Jabatan ini memiliki tanggung jawab dalam pengawasan dan pengawalan program pemerintah di sektor perindustrian, khususnya objek vital nasional dan kawasan industri strategis. Peran Inspektur Jenderal Kemenprin juga mencakup pembinaan penyidik di lingkungan pegawai negeri sipil Kemenperin. Dalam konteks ini, jabatan di luar institusi POLRI yang diemban anggota POLRI Setyo Wasisto masih berpautan dengan fungsi kepolisian, yakni mencegah agar tidak terjadi kesalahan maupun pelanggaran hukum dalam kegiatan di setiap direktorat di Kemenperin. 
Hal serupa juga dapat dilihat pada posisi Dirjen Pemasyarakatan di KemenkumHAM yang dijabat oleh Irjen Pol Reinhard Silitonga. Hampir 50 persen kejahatan narkoba terjadi di lapas dan rutan. Hal ini menuntut KemenkumHAM untuk dapat menyelesaikan permasalahan ini. Atas dasar itu, salah satu tugas Dirjen Pemasyarakatan adalah menyelesaikan permasalahan narkoba di dalam lapas dan rutan. Dengan demikian, tugas Dirjen Pemasyarakatan di KemenkumHAM yang dijabat Irjen Pol Reinhard Silitonga masih memiliki sangkut paut dengan fungsi kepolisian. Oleh sebab itu, walaupun berkerja di luar struktur organisasi POLRI, Irjen Pol Reinhard Silitonga tetap bertugas di bidang fungsi kepolisian. Dengan adanya Anggota POLRI menduduki jabatan ASN dalam rangka fungsi kepolisian, ini juga akan memperlancar koordinasi dengan instansi POLRI dan stakeholders lainnya dalam penegakan hukum (Fahrani, 2018).

\section{Tabel 3}

Posisi Jabatan Anggota POLRI di Luar Institusi Polri dan Sangkut Pautnya dengan Fungsi Kepolisian

\begin{tabular}{llll}
\hline Anggota POLRI & $\begin{array}{l}\text { Posisi } \\
\text { Lembaga/Kementerian/Komisi }\end{array}$ & $\begin{array}{l}\text { Sungkut Paut Kepolisian } \\
\text { Fungan }\end{array}$ & \\
\hline $\begin{array}{l}\text { Komjen Pol Firli } \\
\text { Bahuri }\end{array}$ & Ketua KPK & Penegakan hukum & \\
& & &
\end{tabular}

\begin{tabular}{|c|c|c|}
\hline $\begin{array}{l}\text { Komjen Pol Heru } \\
\text { Winarko }\end{array}$ & Ketua BNN & Penegakan hukum \\
\hline $\begin{array}{l}\text { Komjen Pol Boy } \\
\text { Rafli Amar }\end{array}$ & Ketua BNPT & Penegakan hukum \\
\hline $\begin{array}{l}\text { Irjen } \\
\text { Reinhard } \\
\text { Silitonga }\end{array}$ & $\begin{array}{l}\text { Dirjen Pemasyarakatan } \\
\text { KemenkumHAM }\end{array}$ & Penegakan hukum \\
\hline $\begin{array}{l}\text { Irjen Pol Setyo } \\
\text { Wasisto }\end{array}$ & $\begin{array}{l}\text { Irjen di } \quad \text { Kementerian } \\
\text { Perindustrian (Kemenperin) }\end{array}$ & $\begin{array}{l}\text { Keamanan dan ketertiban; } \\
\text { penegakan hukum }\end{array}$ \\
\hline $\begin{array}{l}\text { Brigadir Jenderal } \\
\text { Adi Deriyan }\end{array}$ & $\begin{array}{l}\text { Staf Khusus bidang Keamanan } \\
\text { Menteri Pariwisata dan } \\
\text { Ekonomi } \\
\text { (Menparekraf) }\end{array}$ & Keamanan dan ketertiban \\
\hline
\end{tabular}

Jabatan yang diisi oleh anggota POLRI aktif di luar struktur organisasi POLRI seperti disampaikan di atas berdasarkan Undang-Undang Aparatur Sipil Negara dan Peraturan Perundang-undang Manajemen PNS 2017 juga merupakan posisi jabatan terbuka untuk diisi oleh anggota POLRI seperti posisi Jabatan Pimpinan Tinggi (JPT). UU No.5/2014 tentang ASN telah memberikan arah pedoman aturan yang mengharuskan adanya kompetisi melalui seleksi secara terbuka ketika memasuki posisi jabatan tinggi (JPT). Persaingan untuk JPT dimungkinkan tidak semata secara internal sesama PNS-ASN, tetapi bisa saja akan bersaing dengan anggota TNI/POLRI, bahkan bisa juga dengan unsur non-PNS (Suharman, 2017). Peraturan Kapolri No. 4 Tahun 2017 juga memungkinkan bagi anggota POLRI aktif untuk 
bertugas di kementerian, lembaga atau komisi. Untuk Anggota POLRI, jabatan JPT di instansi di luar POLRI tersebut yang diperbolehkan adalah sejauh jabatan tersebut masih menyangkut dengan fungsi kepolisian.

Tabel 4

Jenis Jabatan di Luar Institusi POLRI dan Kesesuaian dengan Peraturan/Perundang-Undangan

\begin{tabular}{|c|c|c|c|}
\hline Nama & $\begin{array}{c}\text { Jabatan dan } \\
\text { Lembaga/Kementerian/Komisi }\end{array}$ & $\begin{array}{c}\text { Jenis } \\
\text { Jabatan }\end{array}$ & $\begin{array}{c}\text { Kesesuaian dengan } \\
\text { peraturan/perundang- } \\
\text { undangan }\end{array}$ \\
\hline $\begin{array}{l}\text { Komjen } \\
\text { Pol Firli } \\
\text { Bahuri }\end{array}$ & Ketua KPK & $\begin{array}{l}\text { Jabatan } \\
\text { struktural } \\
\text { / (JPT) }\end{array}$ & $\begin{array}{l}\text { Peraturan Kapolri } \\
\text { No. } 4 \text { Tahun } 2017 \\
\text { Tentang Penugasan } \\
\text { Anggota POLRI di }\end{array}$ \\
\hline $\begin{array}{l}\text { Komjen } \\
\text { Pol Heru } \\
\text { Winarko }\end{array}$ & Ketua BNN & $\begin{array}{l}\text { Jabatan } \\
\text { struktural } \\
\text { / (JPT) }\end{array}$ & $\begin{array}{l}\text { Luar Struktur } \\
\text { POLRI }\end{array}$ \\
\hline $\begin{array}{l}\text { Komjen } \\
\text { Pol Boy } \\
\text { Rafli } \\
\text { Amar }\end{array}$ & Ketua BNPT & $\begin{array}{l}\text { Jabatan } \\
\text { struktural } \\
\text { / (JPT) }\end{array}$ & $\begin{array}{l}\text { - UU No. } 5 \text { Tahun } \\
2014 \text { ASN }\end{array}$ \\
\hline $\begin{array}{l}\text { Irjen Pol } \\
\text { Reinhard } \\
\text { Silitonga }\end{array}$ & $\begin{array}{l}\text { Dirjen Pemasyarakatan } \\
\text { KemenkumHAM }\end{array}$ & $\begin{array}{l}\text { Jabatan } \\
\text { struktural } \\
\text { / (JPT) }\end{array}$ & $\begin{array}{l}\text { - PP No. } 112017 \\
\text { tentang Manajemen } \\
\text { PNS }\end{array}$ \\
\hline $\begin{array}{l}\text { Irjen Pol } \\
\text { Setyo } \\
\text { Wasisto } \\
\end{array}$ & $\begin{array}{l}\text { Irjen di } \quad \text { Kementerian } \\
\text { Perindustrian (Kemenperin) }\end{array}$ & $\begin{array}{l}\text { Jabatan } \\
\text { struktural } \\
\text { / (JPT) }\end{array}$ & \\
\hline $\begin{array}{l}\text { Brigadir } \\
\text { Jenderal } \\
\text { Adi } \\
\text { Deriyan }\end{array}$ & $\begin{array}{l}\text { Staf Khusus bidang Keamanan } \\
\text { Menteri Pariwisata dan Ekonomi } \\
\text { Kreatif (Menparekraf) }\end{array}$ & $\begin{array}{l}\text { Jabatan } \\
\text { Fungsion } \\
\text { al/(JF) }\end{array}$ & \\
\hline
\end{tabular}

Berdasarkan pemaparan di atas, jabatan anggota POLRI aktif di luar institusi seperti di kementerian, lembaga atau komisi sebagaimana dicontohkan di atas tidak menujukkan Dwi Fungsi ABRI sebagaimana di era Orde Baru. Ini karena anggota POLRI aktif tetap bertugas di bidang yang masih terkait dengan fungsi kepolisian walaupun berada di luar struktur organisasi POLRI. Bahkan, pengisian jabatan di luar institusi POLRI itu juga mempertimbangkan aspek kompetensi dan syarat yang sesuai dengan tugas jabatan yang akan diemban. Dengan demikian, posisi yang dijabat oleh anggota POLRI aktif tersebut telah mempertimbangkan aspek latar belakang dan keahlian yang sesuai dengan tugas mereka sebagai anggota POLRI.

\section{Kesimpulan}

Pengisian jabatan di luar struktur organisasi POLRI oleh anggota POLRI terutama di sejumlah kementerian, lembaga atau komisi telah mengundang perhatian sejumlah 
kalangan. Hal tersebut memunculkan isu terkait adanya Dwi Fungsi POLRI", sebuah istilah yang mengingatkan kembali padat Dwi Fungsi ABRI di masa Orde Baru di mana ABRI memiliki fungsi pertahanan dan keamanan sekaligus fungsi kekuatan sosial-politik.

Di masa Reformasi, Dwi Fungsi ABRI telah dihapuskan. Di lingkungan POLRI, hal ini ditandai dengan lahirnya UU POLRI No. 2 Tahun 2002 yang salah satu pasalnya mengatur pembatasan tentang jabatan anggota polisi aktif. Pembatasan tersebut yakni polisi aktif harus mengundurkan diri atau pensiun dari dinas kepolisian jika menduduki jabatan di luar institusi yang tidak terkait dengan fungsi kepolisian. Namun, anggota POLRI masih diperbolehkan menduduki jabatan di luar struktur kepolisian sejauh jabatan tersebut masih memiliki sangkut paut dengan fungsi kepolisian.

Berdasarkan hasil dan pembahasan yang disampaikan, posisi yang diduduki oleh anggota POLRI aktif di kementerian, komisi dan lembaga masih terkait dengan fungsi kepolisian seperti di BNN, BNPT, KPK, atau Kementerian Kemenkum-HAM. Hal ini menunjukkan walaupun menjabat di luar institusi POLRI, tugas yang dijalankan oleh anggota POLRI aktif masih berhubungan dengan fungsi kepolisian. Selain itu, pengisian jabatan di luar institusi POLRI tersebut dilakukan berdasarkan kompetensi dan keahlian mereka. Dalam konteks ini, maka kedudukan anggota POLRI aktif yang menjabat di beberapa kementerian, komisi dan lembaga, hal tersebut tidaklah mencerminkan suatu bentuk Dwi Fungsi ABRI karena anggota POLRI kendati bertugas di luar institusi POLRI, tugas dan wewenang yang dijalankan masih di bidang yang sama yakni fungsi kepolisian. 


\section{BIBLIOGRAFI}

Danendra, I. B. K. (2012). Kedudukan dan Fungsi Kepolisian dalam Struktur Organisasi Negara Republik Indonesia. Lex Crimen, I(4), 41-59.

Endiarti, J. J. (2019). Analisis Implementasi Kebijakan Pengisian Jabatan Pimpinan Tinggi dan Pengangkatan dalam Jabatan Administrasi di Lembaga Ketahanan Nasional. Civil Service: Jurnal Kebijakan dan Manajemen PNS, 13(No.2), 3950 .

Fahrani, N. S. (2018). Analisis Kriteria dan Syarat Jabatan ASN tertentu yang dapat Diisi dari Anggota POLRI dan Prajurit TNI. Civil Service, 12(No.12), 139-154.

Iqbal, Muhammad. (2019). Jenderal Polisi Menyebar di Luar Polri, Dari BUMN Hingga PSSI. di akses https://www.cnbcindonesia.com/news/20191128142831-4 118725/jenderal-polisi-menyebar-di-luar-polri-dari-bumn-hingga-pssi diakses 3 Februari 2021

CNN. (2019) Duduk Manis Jenderal Polisi di Jabatan Sipil Era Jokowi https://www.cnnindonesia.com/nasional/20200630144023-12-519071/dudukmanis-jenderal-polisi-di-jabatan-sipil-era-jokowi/1 diakses 2 Februari 2021.

Limanjaya, R. (2020). Penunjukan Anggota POLRI Aktif untuk Menduduki Jabatan di Luar Kepolisian Ditinjau dari Asas Kepastian Hukum. Jurnal Hukum Adigama, 3(2), 826-845.

Mahardika, A. G. (2020). Rekonstruksi Syarat Pengangkatan Jabatan Komisaris BUMN: Antara Idealita dan Realita. Majalah Hukum Nasional, 50(1), 45-59. https://doi.org/10.33331/mhn.v50i1.51

Patilima, Hamid. (2007). Metode Penelitian Kualitatif. Bandung: Alfabeta.

Peraturan Kapolri No. 4 Tahun 2017 Tentang Penugasan Anggota POLRI di Luar Struktur POLRI.

Peraturan Pemerintah No. 15 Tahun 2001 tentang Pengalihan Status Anggota TNI dan Anggota POLRI Menjadi PNS.

Peraturan Pemerintah Nomor 112017 tentang Manajemen Pegawai Negeri Sipil.

Peraturan Polisi Nomor 12 Tahun 2018 Tentang Perubahan Perkap Nomor 4 Tahun 2017 Tentang Penugasan Anggota Polri Di Luar Struktur Organisasi.

Peter Mahmud Marzuki. (2005). Penelitian Hukum. Jakarta: Prenada Media.

Pusat Bahasa. (2008). Kamus Bahasa Indonesia. Jakarta: Departemen Pendidikan Nasional. 
Ridha, C., \& Wijaya, C. (2020). Analisis Strategi Manajemen Sumber Daya Manusia Dalam Fenomena Bottle-Neck Pamen POLRI. JIANA (Jurnal Ilmu Administrasi Negara), 16(9), 24-35.

Rikan, K. (2014). Konsep Dwifungsi ABRI dan Perannya Dimasa Pemerintahan Orde Baru Tahun 1965-1998. Fakultas Keguruan dan Ilmu Pendidikan, Universitas PGRI Yogyakarta.

Sinaga, F. A. (2018). Legalitas Penunjukan Pejabat POLRI Menjadi Pelaksana Tugas Gubernur Pada Masa Kampanye Pemilihan Kepala Daerah. Jurnal Legislasi Indonesia, 15(1), 63-73. http://e-jurnal.peraturan.go.id/index.php/jli/article/view/16

Soerjono Soekanto dan Sri Mamuji. (2011). Penelitian Hukum Normatif (Suatu Tinjauan Singkat). Jakarta: Rajawali Pers.

Suharman, E. (2017). Kewenangan Pejabat Pembina Kepegawaian Dalam Pengisian Jabatan Pimpinan Tinggi Pratama Di Daerah Menurut Undang-Undang Nomor 5 Tahun 2014 Tentang Aparatur Sipil Negara. Jurnal IUS Kajian Hukum dan Keadilan, 5(2), 219. https://doi.org/10.29303/ius.v5i2.467 